\title{
Long-Term Neurological and Behavioral Results of Biodegradable Scaffoled mplantation in Mice Brain
}

DOI: 10.17691/stm2016.8.4.25

ReceivedMay 19, 2016

A.v. Balyabin, MD, PhD, Researcher, Neurosurgery Department';

O.P. Tikhobrazova, PhD, Senior Researcher, Experimental Modeling Department, Central Research Laboratory2;

M.S. Muravyeva, $\mathrm{PhD}$ Student ${ }^{3}$.

E.A. Klyuev, Intern?'

A.V. Ponyatovskaya, Intern?;

O.M. Shirokova, Junior Researcher, Molecular and Cellular Technology Department,

Central Research Laboratory2; PhD Student3;

K.N. Bardakova, Junior Researcher";

N.V. Minaey, PhD, Senior Research Fellow';

A.V. Koroleva, PhD, Researcher, Nanotechnology Unit5;

Y.I. Mitaeva, PhD, Junior Researcher, Department of Neurotechnology, Institute of Biology and Biomedicine;

E.V. Mitroshina, PhD, Senior Researcher, Molecular and Cell Technologies Department,

Central Research Laboratory2; Senior Researcher, Laboratory for Neuroprotection Methods Development, Institute of Biology and Biomedicine?

M.V. Vedunova, DSc, Director of the Institute of Biology and Biomedicine ${ }^{3}$; Research Fellow,

Laboratory of Laser Chemistry";

Y.A. Rochev, BSc, MSc, PhD, Lecturer, School of Chemistry6; Leading Researcher?;

B.N. Chichkov, DSc, Professor, Head of the Nanotechnology Unit5;

P.S. Timashev, DSc, Head of the Novel Biomaterial Unit7; Senior Researcher, Laboratory of Laser Chemestry4;

V.N. Bagratashvili, DSc, Professor, Head of the Unit of Laser Atomic and Molecular Nanotechnologies4;

I.V. Mukhina, DSc, Professor, Leading Researcher, Biotechnology Department';

Head of the Central Research Laboratory; Head of the Department Normal Physiology

named after N.Y. Belenkov2; Professor, Department of Neurotechnology, Institute of Biology and Biomedicine;

Head of the Center of Translational Technology ${ }^{3}$

'Privolzhsky Federal Research Medical Center, Ministry of Health of the Russian Federation,

18 Verkhne-Volzhskaya naberezhnaya St., Nizhny Novgorod, 603155, Russian Federation;

${ }^{2}$ Nizhny Novgorod State Medical Academy, 10/1 Minin and Pozharsky Square, Nizhny Novgorod, 603005,

Russian Federation;

${ }^{3}$ Lobachevsky State University of Nizhni Novgorod, 23 Prospect Gagarina, Nizhny Novgorod, 603950,

Russian Federation;

${ }^{4}$ Institute of Photon Technologies, Federal Scientific Research Center "Crystallography and Photonics" of the Russian Academy of Sciences, 2 Pionerskaya St., Moscow, Troitsk, 142190, Russian Federation;

${ }^{5}$ Laser Zentrum Hannover, 8 Hollerithallee, Hannover, 30419, Germany;

${ }^{6}$ National Centre for Biomedical Engineering Science, National University of Ireland, Galway (NUI Galway),

University Road, Galway, Ireland;

${ }^{7}$ Institute of Regenerative Medicine, I.M. Sechenov First Moscow State Medical University, 8/2 Trubetskaya St.,

Moscow, 119991, Russian Federation

The aim of the study was to assess the integral outcomes of implantation biocompatible scaffold as the carrier of neural stem cells in the reconstructive surgery of open traumatic brain injury (TBI) by parameters of neurological and cognitive status of the animals in the experiment.

Materials and Methods. Adult male C57BL/6 mice were injured with open-skull weight-drop method. 3D hydrogel scaffold based on modified chitosan in complex with hyaluronic acid was transplanted into the lesion cavity 1 week after TBI. Using a variety of behavioral and cognitive tests (modified neurological severity scores (mNSS), open field test as well as novel object recognition and passive avoidance tests) the short- and long-term neurological and memory functions sequelae induced by TBI were assessed. Magnetic resonance imaging was used to visualize the injury site.

Results. Significant functional recovery was observed on both the mNSS and open field tests in the scaffold transplantation group compared to the control TBI group. In addition, enhanced improvement of short and long-term memory functions was found 5 months post injury. Magnetic resonance imaging data revealed that the scaffold transplantation result in decreasing of the volume of injury area compared to control TBI group and preventing the disruption of the neural networks of the brain.

For contact: Olga P. Tikhobrazova, e-mail: olga.tikhobrazova@gmail.com 
Conclusion. Taken together, our findings indicated that transplantation of 3D biodegradable scaffold into injury cavity contributed to the preservation of volume in the damaged region in the first months after TBI which in turn led to a better functional recovery in the remote period.

Key words: biodegradable scaffolds; functional recovery; traumatic brain injury.

Introduction. The problem of treating the consequences of severe traumatic brain injury, stroke and other neurodegenerative processes is the most complex and socially significant problem of modern medicine, both in Russia and worldwide, because this pathology is one of the main causes of mortality and disability in it, as a result of decline in cognitive capacity [1, 2]. It is known that the degree of neurological deficit in such diseases is determined by two main factors: primary, the direct mechanical damage, leading to nerve cell death and tissue necrosis, and secondary, associated with subsequent activation of the biological factors of inflammation, apoptosis and ischemia of tissues [3-5]. New therapeutic approaches in neurotransplantation targeted at reducing negative consequences, primarily, it is these secondary lesions [6]. Recent studies suggest that adult neural stem/progenitor cells residing in the neurogenic regions in the adult mammalian brain may play regenerative and reparative roles in response to CNS injuries or diseases [7]. For example, selective stimulation of gene expression of neurotrophic factors, leading to activation of reparation processes, such as neurogenesis and synaptogenesis may contribute to reparative remodeling of the nervous tissue with improvement in behavioral and cognitive functions [8]. However, no significant advances in medical therapy and a limited regenerative potential of the brain cause the need for further research of both fundamental mechanisms of regeneration of damaged brain areas, and also the development of fundamentally new methodological approaches to treatment [9].

The first clinical studies of stem cell transplantation patients with consequences of craniocerebral and spinal cord injuries have demonstrated not only clinical efficacy, but immunological and safety of the method [10]. The studies also noted that, despite the limited amount and extent of growth of regenerating axons beyond the lesions and transplantation, the transplanted olfactory cells contribute to the improved functioning of local neural networks in the brain and spinal cord and ascending pathways to the somatosensory cortex [11].

In recent years, the results show that to achieve maximum therapeutic effect of transplantation necessary to use a set of cells from the olfactory epithelium, including fibroblasts, astrocytes, Schwann cells, multipotent stem and neural progenitor cells [12, 13]. In an alternative method can be used transplantation of neural cells on the matrix-carrier (scaffold), as a potentially new strategy for the recovery and regeneration of damaged brain [14]. The most relevant is the development of adequate matrix for transplanted cells that would produce a specific microenvironment with prolonged recovery process, neural networks, and support the structure of brain tissue before its restoration [15-17].

The aim of the study was to assess the integral outcomes of implantation biocompatible scaffold as the carrier of neural stem cells in the reconstructive surgery of open traumatic brain injury by parameters of neurological and cognitive status of the animals in the experiment.

\section{Materials and Methods}

Scaffold's materials. For scaffold fabrication we used chitosan ( $80 \mathrm{kDa}$, the degree of acetylation of 0.15 ) obtained through solid-state synthesis in accordance with the work [18] and methacrylated hyaluronic acid obtained by Streptococcus equi-derived hyaluronic acid sodium salt (high molecular weight, CAS 9067-32-7) following the method [19] (60\% degree of substitution, the reaction yield is $88 \%$ ) in a ratio $3 / 1$. As the photoinitiator used $1 \mathrm{wt} \%$ Irgacure 2959 (99\%, Ciba, Switzerland), the preparation of the photosensitive composition was performed using a protocol previously described in ref [20].

Hydrogel scaffold preparation via two-photon polymerisation. The scaffold was formed directly in the volume of the photosensitive composition by two-photon photopolymerization [18] on the installation of Micro-3Dimensional Structuring System (Laser Centre Hannover) using a second harmonic of femtosecond laser TeMa-100 (Avesta Project, Russia). The hydrogel structures were fabricated using computer-aided design (CAD) models by layer-by-layer technique. The model is a hexagonal array of mutually connected hollow cylinders of $250 \mu \mathrm{m}$ in height, outer diameter of $250 \mu \mathrm{m}$ and an inner diameter of $150 \mu \mathrm{m}$. Crosslinked structures were obtained with about $3 \mu \mathrm{m}$ diameter and $250 \mu \mathrm{m}$ in height (Figure 1). The development of the fabricated structures was performed in distilled water until the unpolymerized material was removed.

\section{Culture preparation}

Animals. Adult male C57BL/6 mice (12-14 weeks of age, 22-25 g) were purchased from the Department of Experimental Animals, Pushchino, Russia, and maintained under standard housing conditions (temperature: $18-24^{\circ} \mathrm{C}$; relative humidity: $45 \%$; light and dark cycle: 12:12 h). Food and water were provided ad libitum. All animals were treated according to the protocols evaluated and approved by the "Guide for care and use of laboratory animals" (ILAR publication, 1996, National Academy Press), Russian Federation standard 330442014 "Principles of Good Laboratory Practice (GLP)" and the Ethical Committee of the Nizhny Novgorod State Medical Academy. 


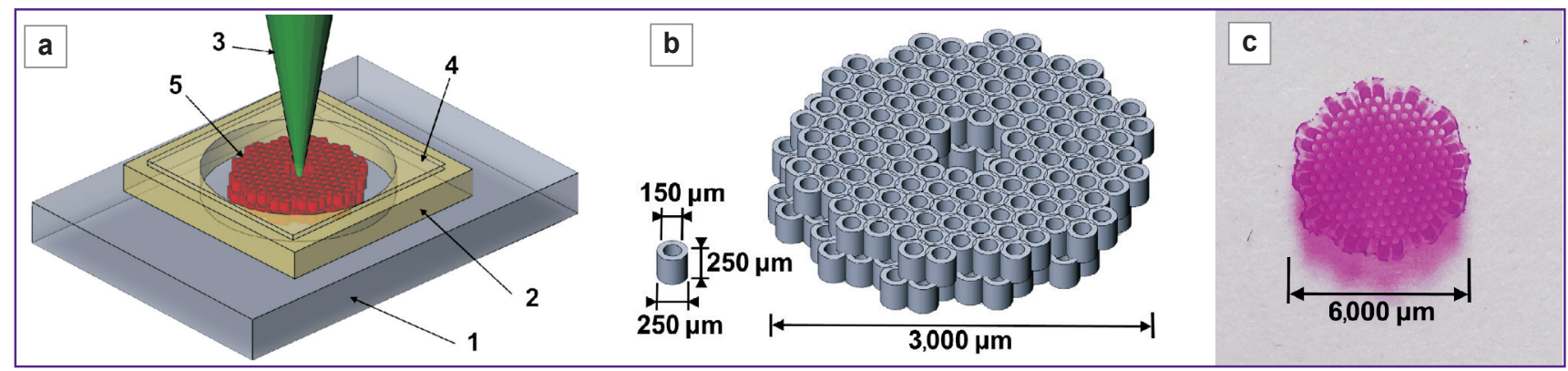

Figure 1. (a) Schematic illustration of the structure formation in the hydrogel: glass slide (1), silicone spacer (2), which housed the photosensitive composition (3), cover glass (4), scaffold (5). (b) Applied 3D model of the two-layer scaffold. (c) Microscopic images of monolayer scaffold after washing of non-crosslinked material in deionized water, the sample was painted to improve the picture's contrast by Rose Bengal (Acros Organics, Belgium)

Substances. Dulbecco's modified Eagle's medium/ Ham's F12 (DMEM-F12), basic fibroblast growth factor (bFGF), epidermal growth factor (EGF), fetal bovine serum (FBS) were purchased from PanEco, Russia. Hank's balanced salt solution (HBSS), trypsin-EDTA $(0.25 \%)$, L-glutamine, $\mathrm{N}-2$ supplement, B-27 supplement were purchased from Gibco, USA. Gentamicin (4\%) was purchased from KPKA, Russia. Poly(ethyleneimine) solution was purchased from Sigma, USA.

Methods. The olfactory mucosa was isolated from the nasal cavity of the mice after decapitation and washed in HBSS. After washing, the olfactory mucosa was mechanically dissociated in HBSS using a scalpel and incubated for $5 \mathrm{~min}$ at $37^{\circ} \mathrm{C}$ in $2 \mathrm{ml}$ trypsin-EDTA $(0.25 \%)$. In the tube, using a sterile plastic pipette, dissociate the tissue. Then $4 \mathrm{ml}$ DMEM-F12 supplemented with $10 \%$ FBS was added to inhibit the trypsin. The dissociated cells were centrifuged at $1,000 \mathrm{~g}$ for $5 \mathrm{~min}$ and resuspended in the growth medium. Cell cultures were grown in DMEM-F12 supplemented with $10 \%$ FBS and gentamicin $100 \mu \mathrm{g} / \mathrm{ml}$ at $37^{\circ} \mathrm{C}$ in a $60 \mathrm{~mm}$ plastic Petri dishes in a humidified $5 \% \quad \mathrm{CO}_{2}$ atmosphere. Renew the culture medium every 2 to 3 days.
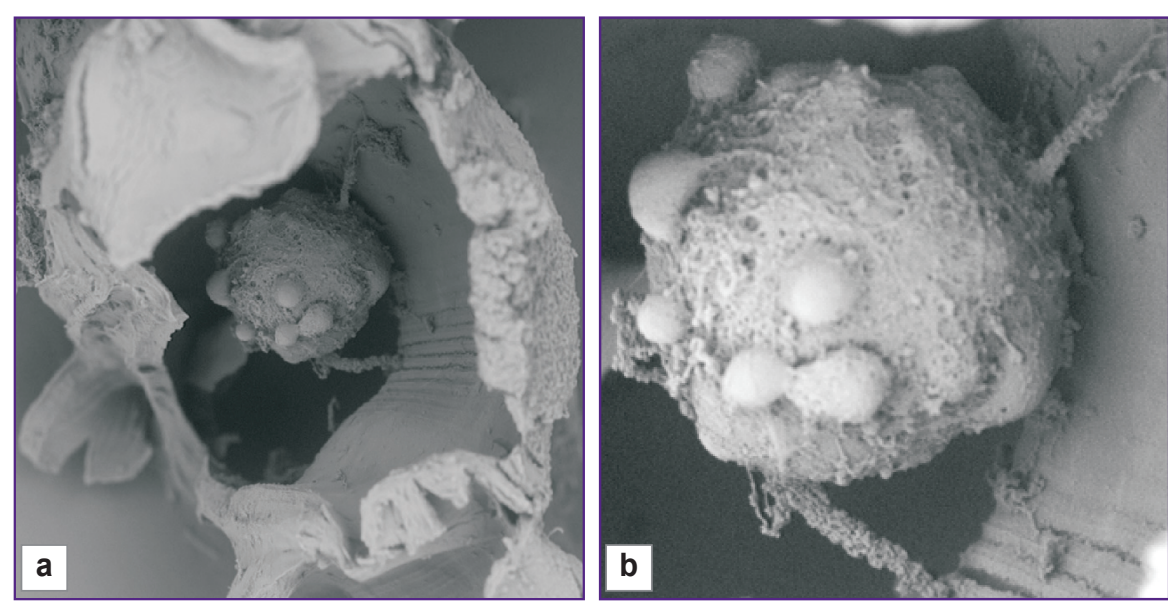

Figure 2. Scanning electron microscope micrographs of the internal structure of scaffolds and the stem cell spheres: (a) scale $50 \mu \mathrm{m}$; (b) scale $25 \mu \mathrm{m}$
Five to seven days after, neural stem cells will begin to invade the culture dish and after two weeks they should be confluent. When confluency is reached, the cells were passaged and transferred to neurosphere forming conditions. To generate stem cell spheres, incubate the Petri dishes for $2 \mathrm{~h}$ at $37^{\circ} \mathrm{C}$ with poly(ethyleneimine) solution. Plate the cells in the treated flasks in culture medium (DMEM/HAM F12 supplemented with insulin, EGF $(50 \mathrm{ng} / \mathrm{ml})$ and FGF2 $(50 \mathrm{ng} / \mathrm{ml}), \mathrm{N}-2$ supplement $(10 \mu \mathrm{l} / \mathrm{ml})$, B-27 supplement $(1.24 \mu \mathrm{l} / \mathrm{ml})$, L-glutamine $(20 \mu \mathrm{l} / \mathrm{ml}))$. Then make medium changes every 3 days. Two to five days later, collect floating and attached cell spheres and either re-plate or dissociate them before grafting in scaffold.

Scanning electron microscopy. The internal structure of scaffold and the change cell growth and morphology were observed under a scanning electron microscopy. The scaffolds with neural stem cells were processed for SEM imaging after the cultivation on 28 day in vitro (DIV). They were fixed with glutaraldehyde $2.5 \%$ for $12 \mathrm{~h}$ and $4{ }^{\circ} \mathrm{C}$, washed three times with bi-distilled water for $15 \mathrm{~min}$. The samples were gradually dehydrated by means of an ethanol series, and then dried using a hexamethyldisilazane (HMDS) for $30 \mathrm{~min}$. Once dried, the samples were sputtered with gold and the images were acquired at $5 \mathrm{kV}$ using scanning electron microscope. SEM micrographs illustrated that the surface of scaffold can support the growth of dissociated hippocampal cell cultures in vitro (Figure 2). On 28 DIV cells do not form a continuous monolayer on the surface of scaffold but cells always clustered in groups. Usually groups of cells were directed on surface of the scaffold. Some groups of cells were spherical form and it fixed to the surface of the scaffold 
using a structure similar to the flagellum. The diameter of the cell groups is quite different (from 12 to $100 \mu \mathrm{m}$ ). In most cases, the diameter of the cells was comparable to the diameter of the control group cells $(7.89 \pm 1.75 \mu \mathrm{m})$. However, groups of cells with cell diameters of $3.35 \pm 1.14 \mu \mathrm{m}$ was found, which formed a group of smallgroup. The morphology of individual cells was similar to the cells grown on the glass.

\section{Weight-drop traumatic brain injury model}

Animals. Adult male C57BL/6 mice (10-12 weeks of age, 20-22 g) were purchased from the Department of Experimental Animals, Pushchino, Russia, and maintained under standard housing conditions (temperature: $18-24^{\circ} \mathrm{C}$; relative humidity: $45 \%$; light and dark cycle: 12:12 h). Food and water were provided ad libitum. All animals were treated according to the protocols evaluated and approved by the "Guide for care and use of laboratory animals" (ILAR publication, 1996, National Academy Press), Russian Federation standard 33044-2014 "Principles of Good Laboratory Practice" and the Ethical Committee of the Nizhny Novgorod State Medical Academy. The number of mice used and their suffering were minimized.

Model. Producing a clinically relevant trauma brain injury (TBI) model in small-sized animals remains fairly challenging: animal models of TBI should be established and standardized [21]. In this study, we established mouse models of head injury using the Feeney weightdrop method [22] with some modifications concerning cognitive deficiency assessment and creating penetrating head injury for next reconstruction of temporary cavities in the severe TBI animal model. Recapitulation of temporary cavities that are induced by high-velocity penetrating objects (fluid percussion) in the mouse brain is difficult to produce [23]. We found that $4 \mathrm{~g}$ falling weight from $80 \mathrm{~cm}$ height produced severe penetrating head injury in C57BL/6 male mice. Cognitive disorders in mice with severe penetrating head injury could be detected using passive avoidance test on day 7 after injury. Findings from this study indicate that weight-drop injury animal models are similar to those seen in human TBI and are suitable for further screening of scaffolds for tissue neuroengineering applications.

Spontaneously breathing mice were anesthetized with $1.5 \%$ isoflurane in oxygen and placed in a stereotaxic frame adapted for mice Narishige (Japan) on a $37.8^{\circ} \mathrm{C}$ heating pad. For inducing focal brain injury, the animals are placed on non-flexible steel platform in order to minimize dissipation of energy [24], to reduce the risk of jaw fractures and achieve of the horizontal location of the calvarium to the tip of weight. All animals underwent craniotomy under aseptic conditions using a surgical microscope. The scalp was shaved and cleansed with chlorhexidine and povidone-iodine wash. The scalp and periosteum were opened, and a left craniotomy $(4 \mathrm{~mm}$ in diameter, $2 \mathrm{~mm}$ posterior to stereotaxic bregma and $2 \mathrm{~mm}$ lateral to the midline) was performed with a fine drill, leaving the dura intact. A weight-drop device was placed over the dura. A sterile polypropylene cylindrical tube was manufactured with a 4-mm opening at one end. Then, a $4 \mathrm{~g}$ weight stainless steel cylinder was dropped from $80 \mathrm{~cm}$ through a guiding tube onto the burr hole to create a contusion brain injury model.

$\mathrm{TBI}$ results in an ipsilateral injury with cortical contusion, hemorrhage, dura rupture that is typically for severe head trauma. After injury, the scalp incision was closed tightly with polypropylene suture and treated with an antiseptic solution. The mice were allowed to recover on a heating pad before being returned to their home cages with postoperative care and ad libitum access to food and water.

Transplantation. Seven days after TBI, mice were again anesthetized as above and placed in a stereotaxic frame. The lesion cavity induced by TBI was exposed in the left hemisphere. A $3 D$ biodegradable scaffold $(2 \times 1 \mathrm{~mm})$ was placed directly into the cavity without removal of additional brain tissue, and then the incision was closed with absorbable surgical suture. TBI control treatment animals underwent identical procedures, with the injections only consisting of the PBS vehicle $(30 \mu \mathrm{l})$. The animals of intact group were not subjected to anesthesia, modeling TBI and transplantation. Sham-injured mice received similar surgical procedures including a craniotomy but no TBI.

Experimental groups. Adult male C57BL/6 mice $(n=40)$ were randomly assigned to four groups. The first group $(n=10)$ includes intact animals. The second group $(n=10)$ comprised sham-operated animals. Mice of the third TBI control group $(n=10)$ were subjected to TBI and injected with saline into the lesion cavity. The fourth group $(n=10)$ was "TBI + scaffold" group.

Injury day was considered as day 0 . All treatments were performed one week after TBI. Animals in the $\mathrm{TBI}$ control group were subjected to TBI and injected intracranially with PBS. Mice in the "TBI + scaffold" group were subjected to TBI, and 7 days later, a scaffold with cultured cells was directly transplanted into the lesion core.

Magnetic resonance imaging (MRI). Imaging of the mice brain was carried out on the high field MRI machine Agilent Technologies DD2-400 9.4 T (400 MHz) with a volume coil M2M $\left(\mathrm{H}^{1}\right)$. Monitoring of the physiological parameters of animals (temperature, respiration and ECG) during imaging was performed on a SA Instruments company (USA) equipment using PC-SAM program. During imaging the animals were under isoflurane anesthesia. Animals were heated by $37^{\circ} \mathrm{C}$ warm air.

MGEMS (multi gradient echo multi slice) pulse sequence with the following parameters: repetition time (TR) is $1,000 \mathrm{~ms}$, echo time (TE, TE2) is $1.5,2 \mathrm{~ms}$, echo number -6 , flip angle -90 , the amount of savings -4 , number of slices - 15, the thickness of slice was $1 \mathrm{~mm}$, the field of vision $-20 \times 20 \mathrm{~mm}^{2}$, matrix size $-128 \times 128$ was used for $\mathrm{T} 2{ }^{*}$-weighted imaging. The total duration of the sequence was 8 min $32 \mathrm{~s}$.

The volume of the injury was calculated by measurement of lesions for each slice and integrating it 
for all slices. ImageJ software was used for operating and analyzing of the MR images.

\section{Behavioral testing}

The modified neurological severity score (mNSS). To evaluate post-traumatic neurologic impairment, all mice were scored on a 10-item rating performance [25] which tests the function of the cortex, the midbrain, and the cerebellum, including motor function, balance, alertness, and physiologic behavior, whereby 1 point is given for failure of the task and no point for succeeding. A maximal neurologic severity score (NSS) of 10 points indicates severe neurological dysfunction, with failure at all tasks. The sum of the scores from the 10 tasks is the NSS. In brief, mice were tested for: 1) the ability and initiative to exit a circle of $30-\mathrm{cm}$ diameter within $3 \mathrm{~min}$; 2) paresis of upper and/or lower limb of the contralateral side; 3) alertness, initiative, and motor ability to walk straight; 4) innate reflex; the mouse will bounce in response to a loud hand clap; 5) physiologic behavior as a sign of "interest" in the environment; 6) ability to balance on a beam of 7-mm width for at least $10 \mathrm{~s}$; 7) ability to balance on a round stick of $5-\mathrm{mm}$ diameter for at least $10 \mathrm{~s}$; 8) ability to cross a $30 \mathrm{~cm}$-long beam of $2 \mathrm{~cm}$ width; 9) ability to cross a $30-\mathrm{cm}$-long beam of $7-\mathrm{mm}$ width; 10) ability to cross a $30-\mathrm{cm}$-long beam of $5-\mathrm{mm}$ width.

The mNSS were determined on the day before TBI and on post injury $1-10,15,20,30$ days, as well as 3,4 and 5 month time points.

Open field test. To assess cortical function, mice were subjected to behavioral testing using of the open field task on day 4 prior to injury (baseline), on post injury 10, 30 days and 3, 4 and 5 months after TBI. Locomotor and exploratory behavior were analyzed. At the beginning of the test individual animals were placed in the center of the square plexiglas open field box (LE800S; PanLab/ Harvard Apparatus Spain; Stoelting, USA) were allowed to freely explore it for $5 \mathrm{~min}$. Traveled distance, mean speed and the number of rearing as well as duration of anxiety-like behavior such as grooming and freezing acts were automatically recorded with a video camera (SONY SSC-G118; Japan). The data acquisition and analysis were controlled with the SMART (Spontaneous Motor Activity Recording and Tracking) v.3.0.03 software (Panlab/Harvard Apparatus Spain; Stoelting, USA). After the test, animals were returned to the home cage. The arena was intensively cleaned after each animal to prevent odor cues.

Novel object recognition (NOR) test. To evaluate deficit in short-term object memory that depends on hippocampal function, particularly those mediated by the dentate gyrus mossy fiber pathway [26] a NOR task was performed 1, 3, 4, 5 months after TBI.

The experimental apparatus consisted of a plexiglas open field box $(45 \times 45 \times 40)$ (LE802S; PanLab/Harvard Apparatus Spain; Stoelting, USA). The procedure consisted of three sessions - habituation, training, and retention - and animals were videotaped during both the training and retention sessions [27; 28]. During the habituation session, the animals were individually habituated to the box, with $10 \mathrm{~min}$ of exploration in the absence of objects for 2 consecutive days to reduce neophobic responses and habituate to the stimuli present in the empty arena. Then, in the first trial, two identical objects were placed in the right and left corners of the box. Mice were placed into the box for $5 \mathrm{~min}$, where they explored the two objects, and the exploratory activity (i.e., time spent in object-directed exploration) was recorded. The cumulative time spent by the mouse exploring each of the objects was recorded. Exploration of an object was defined as follows: directing the nose to the object at a distance of $1 \mathrm{~cm}$ and/or touching it with the nose; turning around or sitting on the object was not considered as exploratory behavior. The animals were immediately taken back to their home cages after the training session. During the retention session $24 \mathrm{~h}$ after the training session, the animals were placed into the same box, but one of the familiar objects used during the training was replaced with a novel object. The objects were different color but similar in size [29]. The animals were then allowed to explore freely for $5 \mathrm{~min}$, and the time spent in exploring each object was recorded. The box was wiped clean with $70 \%$ ethanol between tests. The animals with total exploring time less than $10 \mathrm{~s}$ during both sessions were excluded. Memory function was operationally defined by the discrimination ratio (DIR) for the novel object, as the proportion of time the animals spent investigating the novel object minus the proportion spent investigating the familiar one during the testing period:

DIR=[(novel object exploration time - familiar object

exploration time) / total exploration time] $\times 100$ [30].

Passive avoidance test. The passive avoidance task was used to assess simple non-spatial learning ability. The passive avoidance device comprised of two adjoining compartments, one illuminated and one darkened, divided by a guillotine door. The dimensions of each compartment were $46 \times 27 \times 25 \mathrm{~cm}$. The floor of the compartments consisted of steel rods capable of delivering a slight electric foot shock $(50 \mathrm{~Hz}, 1.5 \mathrm{~mA}$ for $10 \mathrm{~ms})$ to the animal (Shuttle Box LE895; PanLab/Harvard Apparatus Spain; Stoelting, USA). The passive avoidance test was conducted on days 1, 10, 30 and months 3,4 and 5 post injury.

The experiment consisted of three sessions [31]. The animals were placed in the lighted compartment back to the dark compartment (starting position). The door between the compartments was in the open position. After $10 \mathrm{~s}$ the animal was removed from the dark compartment to the living cell. The procedure was repeated 3 times at 30-minute intervals (habituation). The test began by placing the mouse in the lighted compartment at the last attempt to habituation session. As soon as the animal crossed into the dark compartment the guillotine door was closed the animal received a slight electric foot shock (training), and latency for crossing to the dark compartment was recorded with the Shutavoid v.1.8.03 software (PanLab/Harvard Apparatus 
Spain; Stoelting, USA). Following the electric shock, animals were removed from the apparatus and returned to their home cage. Mice were tested for the retention of the passive avoidance response twenty-four hours after the electric shock, and then on day 30 and 3,4 and 5 months after TBI. Upon testing, mice were placed in the illuminated compartment and the latency for the animal to cross into the dark previously shocked compartment, was recorded. During testing, no shock was delivered to the mice. Normal memory response on 3-minute latency of no crossing to the dark compartment was assigned as normal response [32].

Statistical analysis. Results were expressed as mean \pm standard error of the mean (SEM). All data were evaluated for normal distribution and did not meet the assumptions for parametric analysis. Thus, non-parametric analyses were performed using a Wilcoxon signed-rank test for repeated measures of outcomes of the TBI. Statistical comparisons between behavioral data of treatments on each evaluated time-point were performed using a Mann-Whitney $U$ test. A $p$ value of $<0.05$ was considered significant. All data were analyzed using Statistica 5.5 software (StatSoft, USA).

\section{Results}

The neurological status assessment after scaffold transplantation. The functional assessment for mice behavior showed the sustained fault of neurological functions on day 1 after TBI. The mNSS in the groups with brain injury were significantly higher compared with initial level as well as intact and sham-operated groups of animals. Beginning from one-month post injury the mNSS statistically decreased in the group with $3 D$ biodegradable scaffold compared to control PBS group of mice $(p<0.05)$ (Figure 3$)$.

Passive avoidance behavior. The results of behavioral tests revealed the impairment of learning processes of animals in the control (PBS) group as a result of TBI. The entry latency in the control (PBS) group of mice significantly increased compared to intact and sham-operated control group $(p<0.05)$ during the acquisition test. It was caused by the impairment of the motor functions of the CNS of animals owing to the TBI. On day 10 the entry latency into the dark compartment of the shuttle box in the control (PBS) group did not significantly differ from the latency at the acquisition session $(p>0.05)$ (See Figure 3). At the same time the significant increasing of latency was obtained in the group with biodegradable scaffold implantation on day 7 of TBI at the retention test compared with acquisition session as well as in the intact and sham-operated groups of mice (Figure 4). Furthermore, the latency was statistically higher in 3D biodegradable scaffold group compared to control PBS group.

Long-term memory functions were assessed by ability of mice to retain passive avoidance behavior since day 30 of the post-traumatic period. On day 30 after the injury the entry latency at the retention test significantly differed from acquisition session in the scaffold treatment group. From month 3 of the post-traumatic period the latency in this treatment group of mice increased $(p<0.05)$ compared to control PBS group of animals (Figure 5).

Novel object recognition test. Short-term memory of mice was evaluated in the NOR test starting from month 1 of the post-traumatic period. NOR test obtained data showed that TBI results in the significant impairment of hippocampus-dependent working memory (See Figure 4).

The exploratory time of novel object was statistically higher to the familiar object in the group of mice with 3D biodegradable scaffold on day 7 following the injury. Discrimination ratio in this animals group was not differing that in the intact and sham-operated groups of mice on the all observed post-traumatic period. At the same time, the DIR value in the group with scaffold implantation was increased compared to control (PBS) group $(p<0.05)$ that 


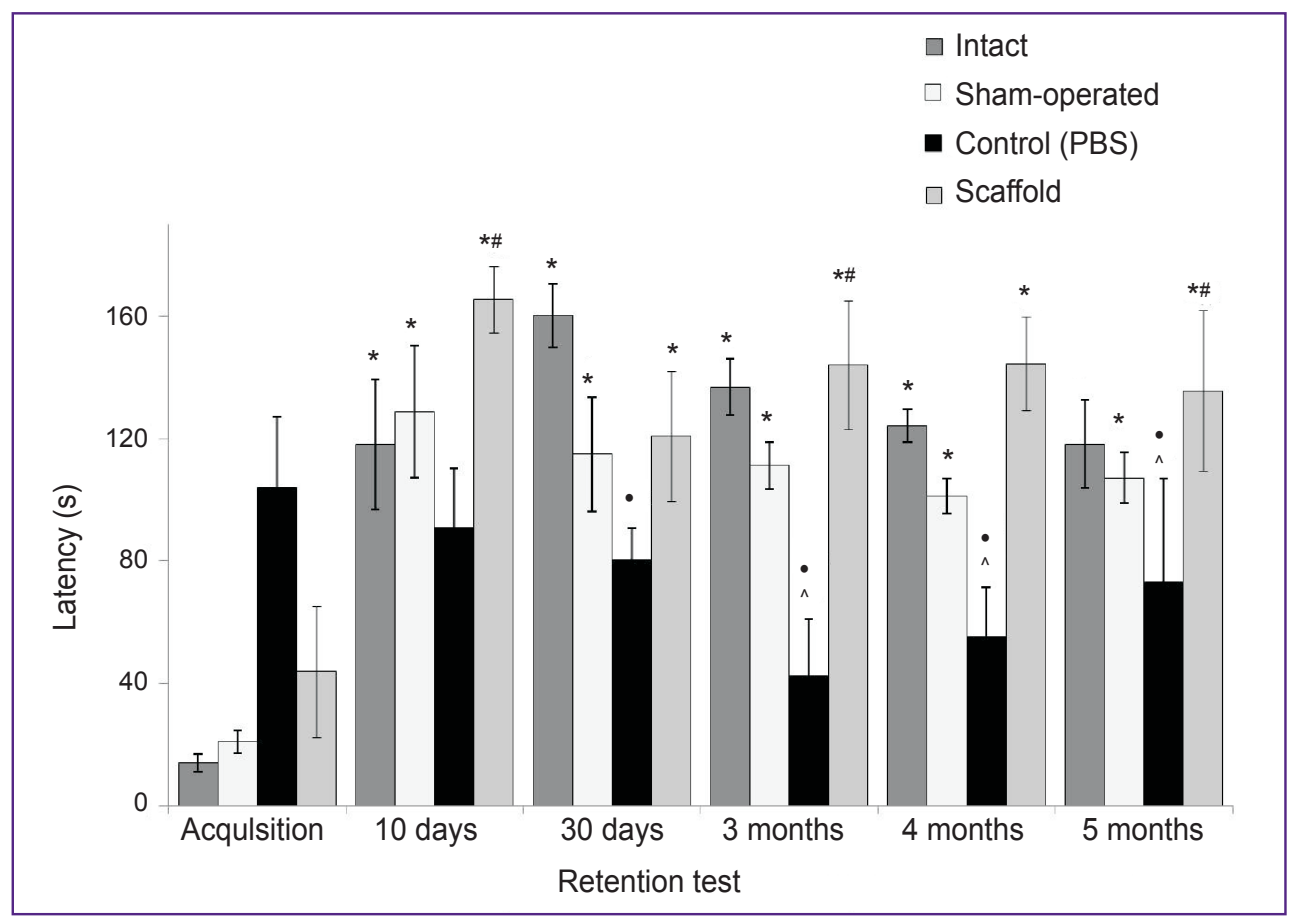

Figure 4. The effect of scaffold implantation on passive avoidance behavior of C57BL/6 mice in the post-traumatic period. The time spent at light compartment during retention test significantly increased compared learning session $\left({ }^{*} p<0.05\right.$; Wilcoxon test). During retention tests control mice demonstrated a decreased latency to entry to dark compartment $\left({ }^{\bullet} p<0.05\right.$ compared to intact mice; ^ $p<0.05$ compared to sham-operated group; Mann-Whitney $U$ test). Scaffold treated group showed significant decreases in time spent in illuminated compartment compared to control group ( ${ }^{p} p<0.05$; Mann-Whitney $U$ test); $n=10$ per group

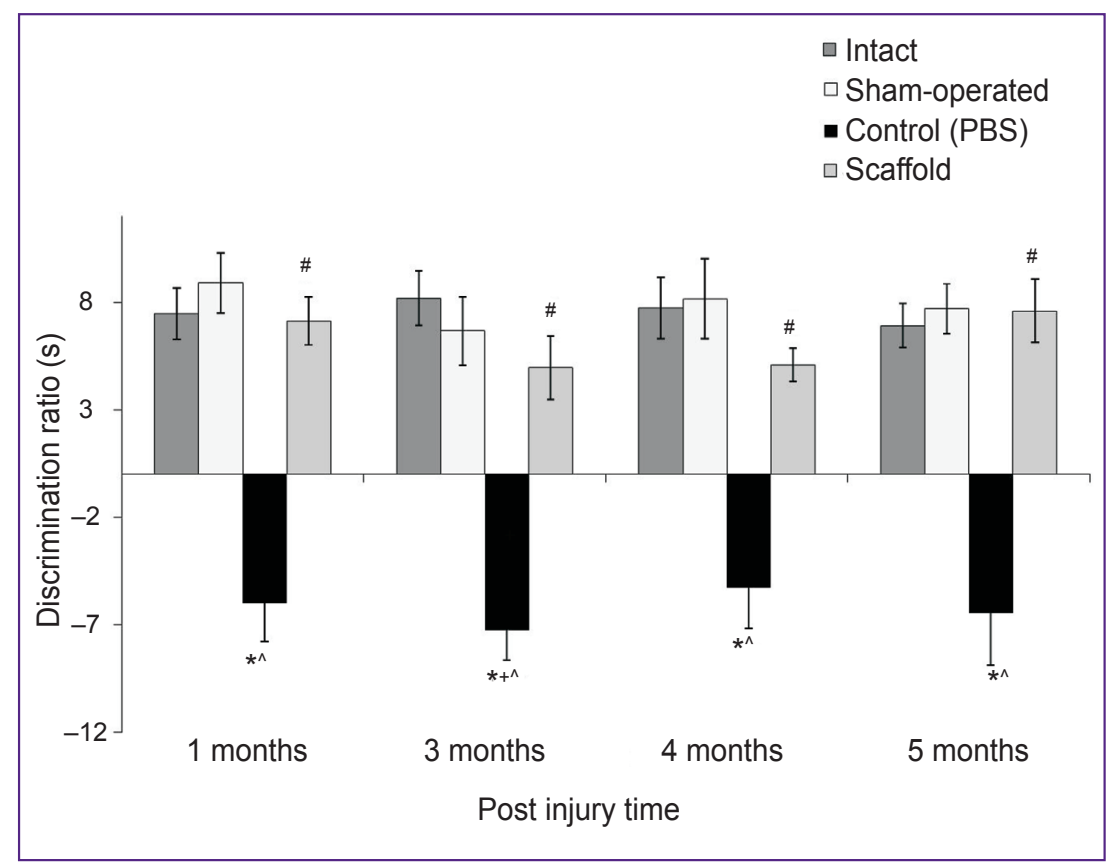

Figure 5. The recovery of C57BL/6 mice recognition memory in the post-traumatic period. Recognition memory was evaluated using the novel object recognition test 1,3 , 4 and 5 months after brain injury. For each mouse in the different groups, the absolute time spent exploring each of the two objects was recorded, and the differences between the exploration time of the two objects were calculated, first, with identical objects and then, $24 \mathrm{~h}$ later, with one of the objects replaced by a new one. The results are expressed as DIR values as described in the text. Statistical analysis of the DIR values of the NOR test results revealed a significant difference of the post-injury time ( ${ }^{+} p<0.05$; Wilcoxon test) as well as between the groups: * $p<0.05$ compared to intact mice; \# $p<0.05$ compared to control group; ^ $p<0.05$ compared to shamoperated group; Mann-Whitney $U$ test; $\mathrm{n}=10$ per group

indicates the recovery of hippocampus-dependent shortterm recognition memory functions (See Figure 4).

Open field test. The data obtained in the open field test revealed the impairment of the motor functions of animals caused by TBI. The implantation of 3D biodegradable scaffold leads to recovery of value of traveled distance. Starting from month 3 of the posttraumatic period it was statistically elevated compared to the control (PBS) mice group $(p<0.05)$ (Figure 6).

The analysis of results showed that TBI leads to 


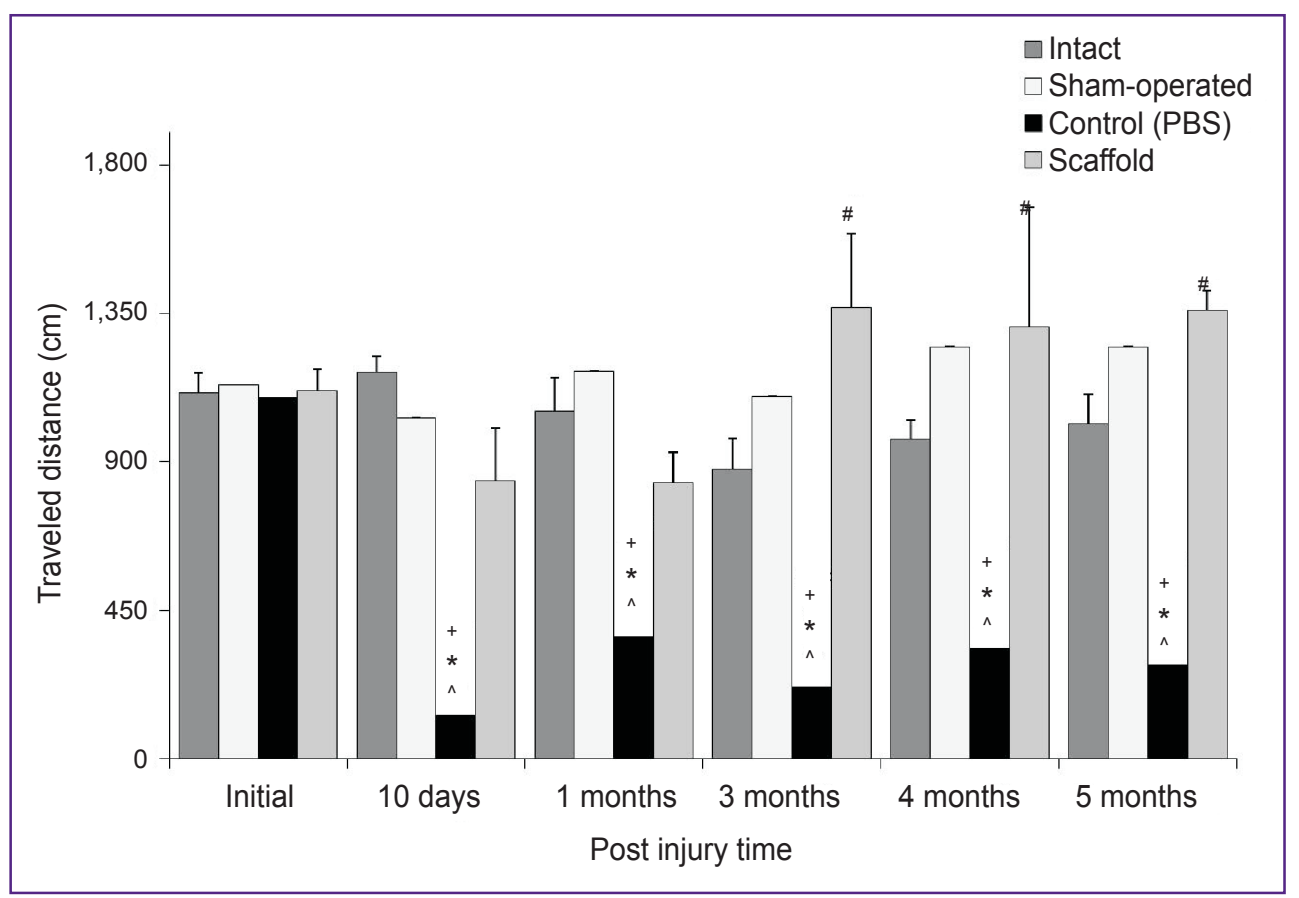

Figure 6. Evaluation of spontaneous motor activity in the post-traumatic period. The assessment of motor activity was determined by measuring the traveled distance in the open field test during $5 \mathrm{~min}$. TBI significantly impaired the motor activity in the post-traumatic period $\left({ }^{*} p<0.05\right.$ values in brain-injured mice that differ significantly from the values in intact mice; $\wedge p<0.05$ compared to sham-operated group; Mann-Whitney $U$ test; ${ }^{+} p<0.05$ significant differences between pre- and postinjured value means; Wilcoxon test). Scaffold implantation significantly increased the distance traveled compared with control mice ( ${ }^{\#}<<0.05$; Mann-Whitney $\cup$ test); $n=10$ per group

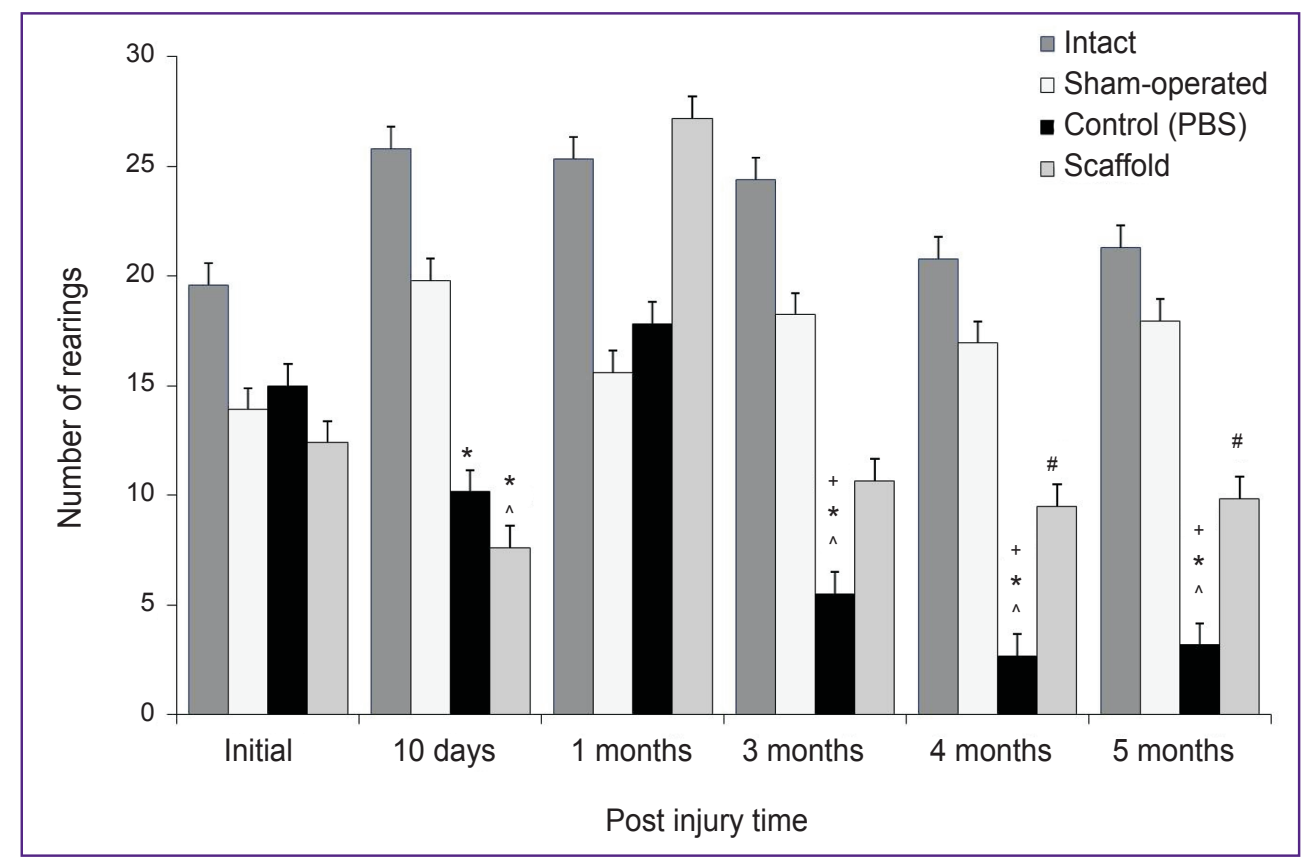

Figure 7. Spontaneous exploratory activity in mice in the post-traumatic period. The assessment of exploratory activity was determined by measuring the number of rearing in the open field test during $5 \mathrm{~min}$. TBI significantly decreased the number of rearing acts $\left({ }^{*} p<0.05\right.$ values in brain-injured mice that differ significantly from values in intact mice; ${ }^{\wedge} p<0.05$ compared to sham-operated group; Mann-Whitney $U$ test; ${ }^{+} p<0.05$ significant differences between pre- and post-injured values means; Wilcoxon test). Scaffold treated group showed significant recovery of exploratory activity compared with control mice ( $\mathrm{p}<0.05$; Mann-Whitney $\mathrm{U}$ test); $\mathrm{n}=10$ per group 


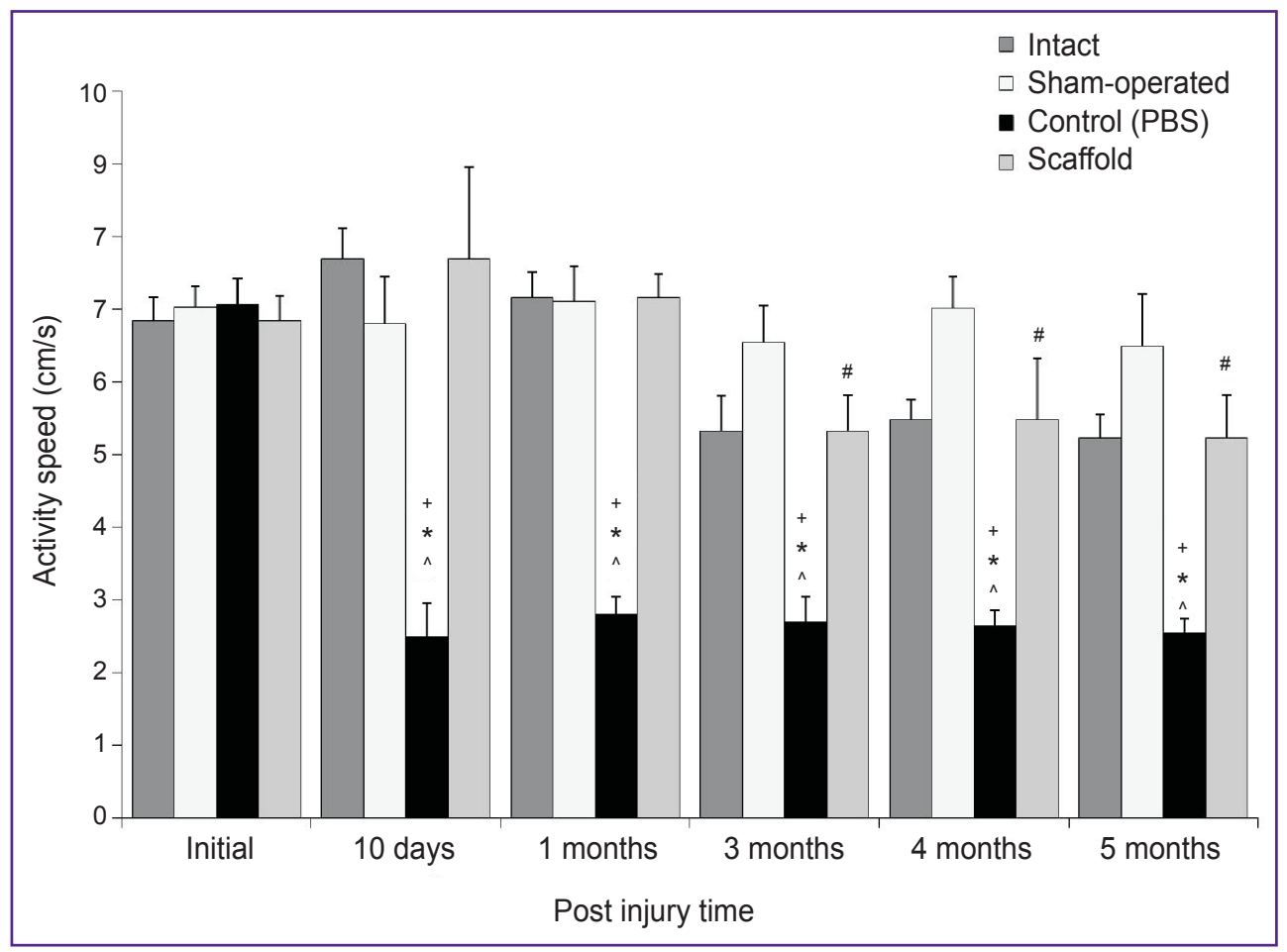

Figure 8. The speed of locomotor activity of C57BL/6 mice in the open field test in the post-traumatic period scaffold implantation prevents activity speed decreasing in the open field test. TBI significantly decreased the speed of activity $\left({ }^{*} p<0.05\right.$ values in brain-injured mice that differ significantly from values in intact mice; ${ }^{\wedge} p<0.05$ compared to sham-operated group; Mann-Whitney $\mathrm{U}$ test; ${ }^{+} p<0.05$ significant differences between pre- and post-injured values means; Wilcoxon test). Scaffold treated group showed significant recovery of the activity speed compared with control mice ${ }^{\#} p<0.05$; Mann-Whitney $\mathrm{U}$ test); $\mathrm{n}=10$ per group

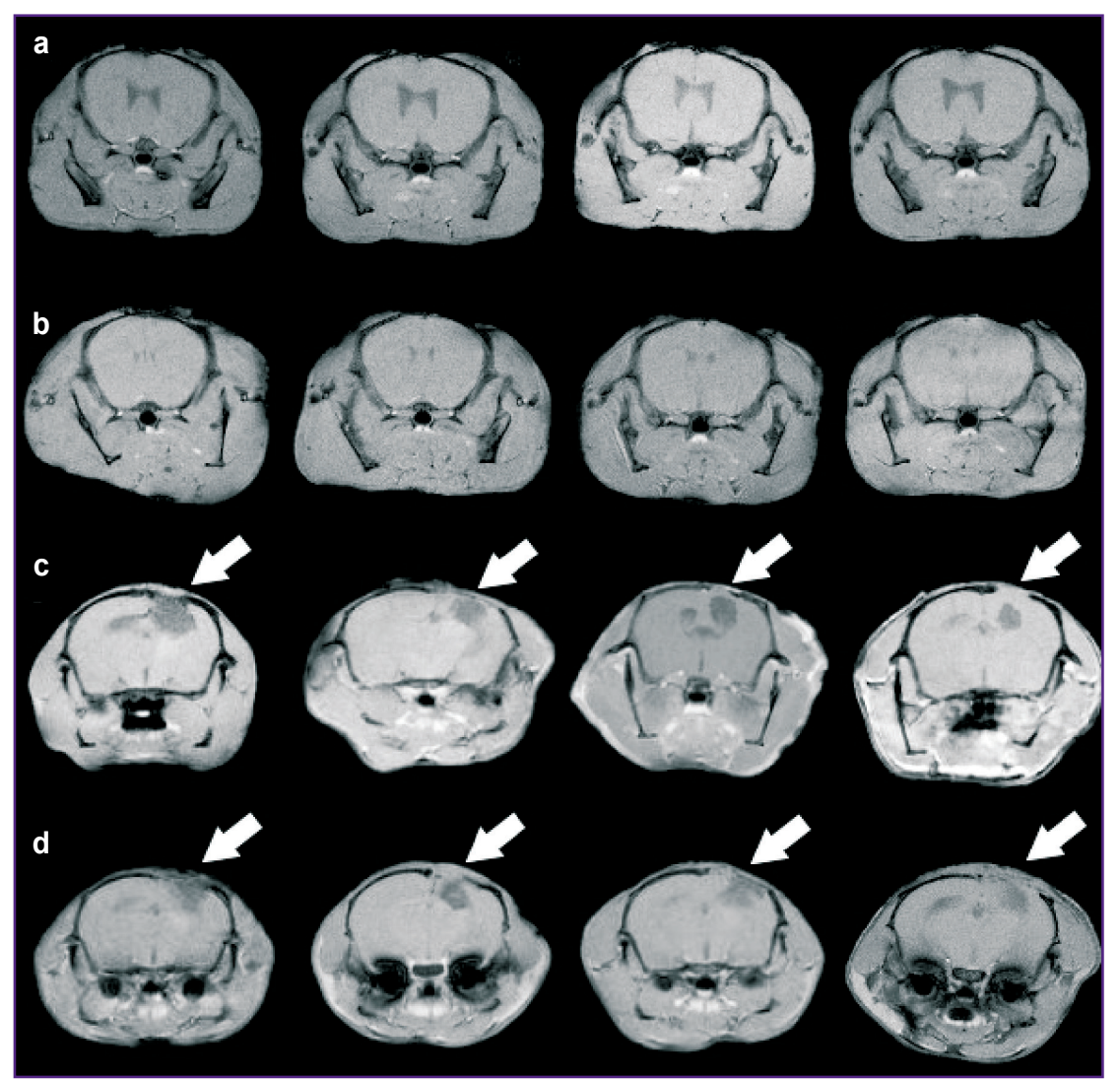

Figure 9. T2*-weighted MR images of the intact mice brain (a), sham-operated mice brain (b), mice with TBI (c) and mice with $\mathrm{TBI}$ and implanted in injury area biodegradable chitosan scaffold (d). Images were obtained using 9.4 T MRI machine, pulse sequence MGEMS 
The volume of the brain tissue injury area obtained by TBI according to the high field MRI $\left(\mathrm{mm}^{3}\right)$

\begin{tabular}{ccccc}
\hline Group of animals & Day 14 & Day 21 & Month 1 & Month 5 \\
\hline Control & $11.32 \pm 1.24$ & $6.98 \pm 0.67$ & $5.38 \pm 0.43$ & $5.12 \pm 0.32$ \\
\hline Scaffold & $15.25 \pm 1.62$ & $16.33 \pm 1.53^{*}$ & $2.83 \pm 0.11^{*}$ & $1.65 \pm 0.12^{*}$ \\
\hline
\end{tabular}

${ }^{*} p<0.05$ compared to control group; Mann-Whitney $U$ test.

significantly impairment of exploratory activity of mice. The number of rearing was decreased in the scaffold treatment group as well as in the control (PBS) group of animals on day 10 compared with intact and shamoperated mice $(p<0.05)$. Starting from one month after injury this factor had recovered in the group of mice with scaffold implantation into injury cavity. Furthermore, it was statistically higher compared to control (PBS) group on months 4 and 5 of the post-traumatic period $(p<0.05)$ (Figure 7).

The TBI results in the decrease of locomotor activity speed of animals. The implantation of 3D biodegradable scaffold had prevented this change. The value of the speed of locomotor activity in this animal group was higher compared to control (PBS) mice since month 3 of the post-traumatic period (Figure 8).

Magnetic resonance imaging data. MRI data obtained 5 months after injury showed that the tissue formed at the site of the scaffold, is not similar to the intact brain tissue on the MR images and structural changes are there (Figure 9). Accumulation of fluid in the injury area was not observed, it would be seen as hyperintense signal and overexposed area on the MR image with the less volume of the brain tissue injury area on month 5 (See the Table). Also, there was no hardening of tissue in the injury area, which could indicate hypointense signal and intensity decline (blackout).

Discussion. At the present time the works in the field of neurotransplantation are more focused on the use of hydrogel systems of different composition with engrafted progenitor cells.

Firstly, the pore structure of the hydrogel allows cells and nutrients to penetrate into the matrix and metabolic products to dispose in the volume of the body [33]. Second, hydrogels are optimal in terms of mechanical compatibility with the brain and spinal cord tissue, Young's modulus values are in the range 1,700-2,000 $\mathrm{Pa}$ [34]. The compatibility of the mechanical characteristics is determining during the differentiation of progenitor cells [35] and influences overall success of implantation [36]. Third, hydrogels are promising drug compounds in the injury site [37].

In the present study, multifunctional hydrogel scaffolds were formed using the method of two-photon polymerization. With the use of scaffolds to solve a range of problems associated with a defect structure and the inflammatory processes that occur at the site of injury. The structure's composition provided mechanical properties of the scaffold and initiated degradation process in the interaction with the surrounding tissues and body fluids. As the main component a high molecular chitosan was chosen, it used with human mesenchymal stem cells for the TBI therapy [38]. Chitosan is a polysaccharide structurally similar to glycosaminoglycans, it has good mechanical properties, but the long degradation kinetics [39]. On the other hand, it is known that the basis of the extracellular brain matrix is hyaluronic acid and enzymatic degradation of hyaluronic acid results from the action of three types of enzymes are synthesized in the brain tissues: hyaluronidase, $\beta-D$ glucuronidase, and $\beta-\mathrm{N}$-acetylhexosaminidase [40]. Enzymatic degradation of methacrylated hyaluronic acid (up to $2 \mathrm{wt} \%$ in the composition) allowed to initiate the destruction of the structure according to the mechanism of the erosive degradation. Earlier, similar scaffolds on the composition of zirconium based hybrid material were formed by two-photon polymerization. It has been shown that the selected model provides formation of 3-dimensional neural network using primary neuronal cells [41]. By preliminary studies we have found that the scaffold material based on chitosan and hyaluronic acid is non-toxic, biocompatible with dissociated brain cells of mice [20].

Based on these results the corresponding model of the structure has been selected and 3D hydrogel scaffolds on the basis of chemical composition were formed. Since mechanical properties of the scaffold coincide with the mechanical properties of the surrounding tissue, in the experiment did not occur the formation of the fibrous capsule caused by mechanical damage of the extracellular matrix of the brain. In addition, structured hydrogels are used not only in terms of facilitating cell regeneration but also in enacting a form of architectural support to prevent further damage to adjacent tissue [42].

The study shows that the transplantation of the scaffold after 7 days after traumatic brain injury preserves the ability of animals to study conditioned reflexes and updating traces of short and long-term memory after 5 months after injury in contrast to the control. Likely that maintaining brain volume in the post-traumatic period due to the scaffold within the first month, according to MRI, prevents the disruption of the neural networks of the brain, which leads to a better recovery of cognitive and reflex functions of the CNS compared to control.

Conclusion. Behavioral tests revealed a significant improvement in recovery of cognitive and reflex 
functions of the CNS in animals against the backdrop of neurotransplantation. A facilitative effect on the ability of animals to learn passive avoidance reaction and updating traces of short and long-term memory in the remote period was observed.

Morphological and functional parameters of activity of the mice showed the biocompatibility of the biodegradable $3 \mathrm{D}$ scaffold material based on modified chitosan in complex with hyaluronic acid. Transplantation decorated 3D biodegradable structures contributed to the preservation of volume in the damaged region in the first months after injury.

Study Finding. The research was supported by the Federal Target Program "Research and development in priority areas of the development of the scientific and technological complex of Russia for 2014-2020" of the Ministry of Education and Science of Russia (Project ID RFMEFI60715X0117).

Conflicts of Interest. The authors have no conflicts of interest.

\section{References}

1. Gusev E.I., Konovalov A.N., Skvortsova V.I., Hecht A.B. Nevrologiya [Nevrologiya]. Moscow: GEOTAR-Media; 2009; $1040 \mathrm{p}$.

2. Bullock M.R., Chesnut R., Ghajar J., Gordon D., Hartl R., Newell D.W., Servadei F., Walters B.C., Wilberger J.E. Guidelines for the surgical management of traumatic brain injury. Neurosurgery 2006; 58(3), https://doi. org/10.1097/00006123-200603001-00006.

3. Feigin V.L., Barker-Collo S., Krishnamurthi R., Theadom A., Starkey N. Epidemiology of ischaemic stroke and traumatic brain injury. Best Pract Res Clin Anaesthesiol 2010; 24(4): 485-494, https://doi.org/10.1016/j.bpa.2010.10.006.

4. Valadka A.B., Robertson C.S. Surgery of cerebral trauma and associated critical care. Neurosurgery 2007; 61(1): 203221, https://doi.org/10.1227/01.neu.0000255497.26440.01.

5. Greenberg M.S. Handbook of neurosurgery. New York: Thieme Publishers; 2010.

6. Cheng G., Kong R., Zhang L., Zhang J. Mitochondria in traumatic brain injury and mitochondrial-targeted multipotential therapeutic strategies. Br J Pharmacol 2012; 167(4): 699-719, https://doi.org/10.1111/j.1476-5381.2012.02025.x.

7. Liu S.-J., Zou Y., Belegu V., Lv L.-Y., Lin N., Wang T.-Y., McDonald J.-W., Zhou X., Xia Q.-J., Wang T.-H. Co-grafting of neural stem cells with olfactory en sheathing cells promotes neuronal restoration in traumatic brain injury with an antiinflammatory mechanism. J Neuroinflammation 2014; 11(1): 66, https://doi.org/10.1186/1742-2094-11-66.

8. Blaya M.O., Tsoulfas P., Bramlett H.M., Dietrich W.D. Neural progenitor cell transplantation promotes neuroprotection, enhances hippocampal neurogenesis, and improves cognitive outcomes after traumatic brain injury. Exp Neurol 2015; 264: 67-81, https://doi.org/10.1016/j. expneurol.2014.11.014.

9. Dobrowolski S., Lepski G. Stem cells in traumatic brain injury. American Journal of Neuroscience 2013; 4(1): 13-24, https://doi.org/10.3844/amjnsp.2013.13.24.

10. Lima C., Pratas-Vital J., Escada P., Hasse-Ferreira A., Capucho C., Peduzzi J.D. Olfactory mucosa autografts in human spinal cord injury: a pilot clinical study. J Spinal Cord Med 2006; 29(3): 191-203, https://doi.org/10.1080/10790268. 2006.11753874.

11. Toft A., Scott D.T., Barnett S.C., Riddell J.S. Electrophysiological evidence that olfactory cell transplants improve function after spinal cord injury. Brain 2006; 130(4): 970-984, https://doi.org/10.1093/brain/awm040.

12. Ao Q., Wang A.J., Chen G.Q., Wang S.J., Zuo H.C., Zhang X.F. Combined transplantation of neural stem cells and olfactory ensheathing cells for the repair of spinal cord injuries. Med Hypotheses 2007; 69(6): 1234-1237, https://doi. org/10.1016/j.mehy.2007.04.011.

13. Andrews M.R., Stelzner D.J. Evaluation of olfactory ensheathing and Schwann cells after implantation into a dorsal injury of adult rat spinal cord. J Neurotraum 2007; 24(11): 1773-1792, https://doi.org/10.1089/neu.2007.0353.

14. Skop N.B., Calderon F., Cho C.H., Gandhi C.D., Levison S.W. Improvements in biomaterial matrices for neural precursor cell transplantation. Mol Cell Ther 2014; 2(1): 19, https://doi.org/10.1186/2052-8426-2-19.

15. Crompton K.E., Goud J.D., Bellamkonda R.V., Gengenbach T.R., Finkelstein D.I., Horne M.K., Forsythe J.S. Polylysine-functionalised thermoresponsive chitosan hydrogel for neural tissue engineering. Biomaterials 2007; 28(3): 441449, https://doi.org/10.1016/j.biomaterials.2006.08.044.

16. Tate C.C., Shear D.A., Tate M.C., Archer D.R., Stein D.G., LaPlaca M.C. Laminin and fibronectin scaffolds enhance neural stem cell transplantation into the injured brain. J Tissue Eng Regen Med 2009; 3(3): 208-217, https://doi. org/10.1002/term.154.

17. Mo L., Yang Z., Zhang A., Li X. The repair of the injured adult rat hippocampus with NT-3-chitosan carriers. Biomaterials 2010; 31(8): 2184-2192, https://doi.org/10.1016/j. biomaterials.2009.11.078.

18. Timashev P.S., Demina T.S., Minaev N.V., Bardakova K.N., Koroleva A.V., Kufelt O.A., Chichkov B.N., Panchenko V.Ya., Akopova T.A., Bagratashvili V.N. Fabrication of microstructured materials based on chitosan and its derivatives using two-photon polymerization. High Energy Chemistry 2015; 49(4): 300-303, https://doi.org/10.1134/s0018143915040177.

19. Kufelt O., El-Tamer A., Sehring C., Schlie-Wolter S., Chichkov B.N. Hyaluronic acid based materials for scaffolding via two-photon polymerization. Biomacromolecules 2014; 15(2): 650-659, https://doi.org/10.1021/bm401712q.

20. Timashev P.S., Bardakova K.N, Minaev N.V., Demina T.S., Mishchenko T.A., Mitroshina E.V., Akovantseva A.A., Koroleva A.V., Asyutin D.S., Pimenova L.F., Konovalov N.A., Akopova T.A., Solov'eva A.B., Mukhina I.V., Vedunova M.V., Chichkov B.N., Bagratashvili V.N. Compatibility of cells of the nervous system with structured biodegradable chitosan-based hydrogel matrices. Applied Biochemistry and Microbiology 2016; 52(5): 508-514, https://doi.org/10.1134/ s0003683816050161.

21. Khalin I., Jamari N.L., Razak N.B., Hasain Z.B., Nor M.A., Zainudin M.H., Omar A.B., Alyautdin R. A mouse model of weight-drop closed head injury: emphasis on cognitive and neurological deficiency. Neural Regen Res 2016; 11(4): 630, https://doi.org/10.4103/1673-5374.180749.

22. Feeney D.M., Boyeson M.G., Linn R.T., Murray H.M., Dail W.G. Responses to cortical injury: I. Methodology and local effects of contusions in the rat. Brain Res 1981; 211(1): 67-77, https://doi.org/10.1016/0006-8993(81)90067-6.

23. Zhang Y.P., Cai J., Shields L.B., Liu N., Xu X.-M., 
Shields C.B. Traumatic brain injury using mouse models. Trans/ Stroke Res 2014; 5(4): 454-471, https://doi.org/10.1007/ s12975-014-0327-0.

24. Flierl M.A., Stahel P.F., Beauchamp K.M., Morgan S.J., Smith W.R., Shohami E. Mouse closed head injury model induced by a weight-drop device. Nat Protoc 2009; 4(9): 13281337, https://doi.org/10.1038/nprot.2009.148.

25. Tsenter J., Beni-Adani L., Assaf Y., Alexandrovich A.G., Trembovler V., Shohami E. Dynamic changes in the recovery after traumatic brain injury in mice: effect of injury severity on T2-weighted MRI abnormalities, and motor and cognitive functions. J Neurotrauma 2008; 25(4): 324-333, https://doi. org/10.1089/neu.2007.0452.

26. Rolls E.T. The mechanisms for pattern completion and pattern separation in the hippocampus. Front Syst Neurosci 2013; 7, https://doi.org/10.3389/fnsys.2013.00074.

27. Huang T.-N., Chuang H.-C., Chou W.-H., Chen C.-Y., Wang H.-F., Chou S.-J., Hsueh Y.P. Tbr1 haploinsufficiency impairs amygdalar axonal projections and results in cognitive abnormality. Nat Neurosci 2014; 17(2): 240-247, https://doi. org/10.1038/nn.3626.

28. Moscardo E., Salvetti B., Becchi S., Bertini G., Fabene P.F. The novel object recognition test in rodents: which are the essential methodological aspects? Proceedings of Measuring Behavior 2012; 8: 476-478.

29. Levy A., Bercovich-Kinori A., Alexandrovich A.G., Tsenter J., Trembovler V., Lund F.E., Shohami E., Stein R., Mayo L. CD38 facilitates recovery from traumatic brain injury. J Neurotrauma 2009; 26(9):1521-1533, https://doi. org/10.1089/neu.2008-0746.

30. Chen S.T., Chen H.H., Chiang Y.C., Yuan Z.F., Kuo C.C., Lai M.D., Hung T.W., Ho I.K., Chen S.T. Buprenorphine, methadone, and morphine treatment during pregnancy: behavioral effects on the offspring in rats. Neuropsychiatr Dis Treat 2015; 609-618, https://doi. org/10.2147/ndt.s70585.

31. Buresh J., Bureshova O., Houston D.P. Metodiki $i$ osnovnye eksperimenty po izucheniyu mozga $i$ povedeniya [Methods and basic experiments for the study of brain and behavior]. Moscow: Vysshaya shkola; 1991; 398 p.

32. Zohar O., Rubovitch V., Milman A., Schreiber S., Pick C.G. Behavioral consequences of minimal traumatic brain injury in mice. Acta Neurobiol Exp (Wars) 2011; 71(1): 36-45.

33. Cao Z. Developing chitosan-based biomaterials for brain repair and neuroprosthetics. Master of Science Degree
Thesis. University of Tennessee; 2010. URL: http://trace. tennessee.edu/utk_gradthes/609.

34. Engler A.J., Sen S., Sweeney H.L., Discher D.E. Matrix elasticity directs stem cell lineage specification. Cell 2006; 126(4): 677-689, https://doi.org/10.1016/j.cell.2006.06.044.

35. Kaster T., Sack I., Samani A. Measurement of the hyperelastic properties of ex vivo brain tissue slices. $J$ Biomech 2011; 44(6): 1158-1163, https://doi.org/10.1016/j. jbiomech.2011.01.019.

36. Liao H., Munoz-Pinto D., Qu X., Hou Y., Grunlan M.A., Hahn M.S. Influence of hydrogel mechanical properties and mesh size on vocal fold fibroblast extracellular matrix production and phenotype. Acta Biomaterialia 2008; 4(5): 1161-1171, https://doi.org/10.1016/j.actbio.2008.04.013.

37. Khaing Z.Z., Thomas R.C., Geissler S.A., Schmidt C.E. Advanced biomaterials for repairing the nervous system: what can hydrogels do for the brain? Materials Today 2014; 17(7): 332-340, https://doi.org/10.1016/j.mattod.2014.05.011.

38. Carballo-Molina O.A., Velasco I. Hydrogels as scaffolds and delivery systems to enhance axonal regeneration after injuries. Front Cell Neurosci 2015; 9: 13, https://doi. org/10.3389/fncel.2015.00013.

39. Shi W., Nie D., Jin G., Chen W., Xia L., Wu X., Su X., Xu X., Ni L., Zhang X., Zhang X., Chen J. BDNF blended chitosan scaffolds for human umbilical cord MSC transplants in traumatic brain injury therapy. Biomaterials Biomaterials 2012; 33(11): 3119-3126, https://doi.org/10.1016/j. biomaterials.2012.01.009.

40. Miranda D.G., Malmonge S.M., Campos D.M., Attik N.G., Grosgogeat B., Gritsch K. A chitosan-hyaluronic acid hydrogel scaffold for periodontal tissue engineering. J Biomed Mater Res B Appl Biomater 2016; 104(8): 1691-1702, https:// doi.org/10.1002/jbm.b.33516.

41. Timashev P.S., Vedunova M.V., Guseva D., Ponimaskin E., Deiwick A., Mishchenko T.A., Mitroshina E.V., Koroleva A.V., Pimashkin A.S., Panchenko V.Ya., Bagratashvili V.N., Mukhina I.V., Chichkov B.N. 3D in vitro platform produced by two-photon polymerization for the analysis of neural network formation and function. Biomed Phys Eng Express 2016; 2(3): 035001, https://doi. org/10.1088/2057-1976/2/3/035001.

42. Pettikiriarachchi J.T.S., Parish C.L., Shoichet M.S., Forsythe J.S., Nisbet D.R. Biomaterials for brain tissue engineering. Australian Journal of Chemistry 2010; 63(8):1143-1154, https://doi.org/10.1071/ch10159. 